\title{
ERRATUM
}

Jamie S. M. Pringle · Jonathan H. Doust · Helen Carter Keith Tolfrey · Iain T. Campbell · Giorkos K. Sakkas

Andrew M. Jones

\section{Oxygen uptake kinetics during moderate, heavy and severe intensity 'submaximal' exercise in humans: the influence of muscle fibre type and capillarisation}

Published online: 31 March 2004

(C) Springer-Verlag 2004

\section{Eur J Appl Physiol (2003) 89:289-300}

Giorkos K. Sakkas should have been included as a co-author of this paper.

The online version of the original article can be found at http:// dx.doi.org/10.1007/s00421-003-0799-1

J. S. M. Pringle · K. Tolfrey · G. K. Sakkas · A. M. Jones $(\bowtie)$ Department of Exercise and Sport Science,

Manchester Metropolitan University,

Hassall Road, Alsager, ST7 2HL, UK

E-mail: a.m.jones@mmu.ac.uk

Tel.: + 44-161-2475656

Fax: + 44-161-2476375

J. H. Doust

Department of Sport Science, University of Wales Aberystwyth, Aberystwyth, SY23 2AX, UK

H. Carter

School of Sport Exercise and Leisure,

University of Surrey Roehampton, London, SW15 3SN, UK

I. T. Campbell

Deparment of Anaesthesia, Wythenshawe Hospital,

Southmoor Road, Manchester, M23 9LT, UK 